\title{
A Challenge-based Laboratory to Explore Drug Delivery from Swellable Matrices
}

Stephanie Farrell (corresponding author)

Department of Chemical Engineering

Rowan University

201 Mullica Hill Road

Glassboro, NJ 08028-1701

Farrell@rowan.edu

Jennifer Vernengo

Department of Chemical Engineering

Rowan University

201 Mullica Hill Road

Glassboro, NJ 08028-1701

Vernengo@rowan.edu 


\begin{abstract}
This paper describes an experiment that introduces students to drug delivery from swellable matrices (tablets). Students produce hydrophilic polymeric tablets loaded with drug and measure the rate of release from the tablets for systems having different drug loading, polymer composition and polymer molecular weight. Transient concentration data are obtained from drug release studies and analyzed to characterize the release profile and to determine the predominant rate controlling mechanism. The purpose of the experiment is to provide engineering students with basic skills relevant to drug delivery while simultaneously introducing or reinforcing science principles; applications of science, math and engineering; the science and art of design, and data analysis. Students showed significant pre-post gains in several areas, and the gains for each objective between the pre- and post-test ranged from 48-60\%. The average normalized gain between pre-test and post-test was $65 \%$.
\end{abstract}

Keywords: How People Learn, Challenge-based Laboratory, Drug Delivery, Controlled Release 
Stephanie Farrell is a Professor of Chemical Engineering at Rowan University, and she was the Fulbright Scholar in Engineering Education at Dublin Institute of Technology in 20142015. She has made contributions to chemical engineering education through the development of inquiry-based, hands-on projects in areas such as drug delivery, biomedical engineering, food engineering and sustainability.

Jennifer Vernengo is an Associate Professor of Chemical Engineering at Rowan University. Jennifer received her Ph.D. from Drexel University in 2007. She began work as a materials scientist at Synthes Biomaterials, and then joined Drexel University College of Medicine as postdoc in 2009. Jennifer's research is in the area of injectable biomaterials for orthopedic tissue replacement and repair. She is particularly interested in developing innovative approaches to biomedical engineering education. 


\section{Introduction}

Controlled drug delivery is a burgeoning field that represents a major growth driver of the pharmaceutical industry today: the global drug delivery technology segment has grown from $\$ 15$ billion in 2000 to $\$ 50$ billion in 2008 , representing an average compound annual growth rate of $18 \%$ in comparison with $10 \%$ for the overall pharmaceutical market (Pannelay 2009). The field has grown tremendously, driven in part by the innovations of chemical engineers (Liechty and Peppas 2010) who play an important and expanding role in this exciting and inherently multidisciplinary field.

Controlled drug delivery systems are engineered to deliver a drug to the body at a predetermined rate for an extended time. Controlled release systems have expanded from traditional drugs to therapeutic peptides, vaccines, hormones, and viral vectors for gene therapy. These systems employ a variety of rate-controlling mechanisms, including matrix diffusion, membrane diffusion, biodegradation and osmosis (Langer 1990). The interdisciplinary training of an engineer enables him/her to make a unique contribution to the development of novel drug delivery systems, where an understanding of drug transport, action, metabolism; materials science; and mathematical analysis are essential (Saltzman 2001).

The chemical engineer plays a vital role in the development of new drug delivery systems, and examples of hands-on experiments to introduce chemical engineering students to drug delivery are emerging in the educational literature (Farrell and Hesketh 2002, Farrell and Vernengo 2011, Norman 2011, Xu et al. 2010). This paper describes an experiment that introduces students to drug delivery system design, formulation and analysis from an engineering point of view. Students produce compressed tablets of hydrophilic polymer, obtain release data and analyze the rate of release from the tablets. They investigate the effect of drug loading, polymer composition, and polymer molecular weight on the release rate of the drug. Using Excel and Polymath, students compare their results to a mathematical model in order to determine the rate controlling mechanism of the release. Through this experiment students explore many concepts and tools that they will use throughout their engineering careers:

- Modeling of and application of chemical engineering principles (mass transport and materials)

- Concentration measurement

- Use of spreadsheets for calculating and graphing

- Identification of questions that guide data analysis; 
- Interpretation of the significance of results

- Design of solid dosage form drug delivery systems

This experiment has been implemented in the Freshman Engineering Clinic at Rowan University, and the impact on student learning has been evaluated using an instrument that maps concepts from the lesson to course and lab objectives and ABET objectives. While this paper describes the details of a freshman-level experiment, it may easily be adapted to more advanced courses such as materials science or a bioengineering/drug delivery elective course. A materials science course would focus on the changes in the morphological structure of the swellable tablets that occur with time and how this affects the release mechanism. In an elective course in which there is time for a course project, a factorial design could be used to design a formulation that meets a specific clinical challenge.

Rowan's Freshman Engineering Clinic is a required two-semester course sequence taken by all engineering students. Each section has students from all four engineering majors (Chemical, Civil and Environmental, Electrical and Computer, and Mechanical) who work together in multidisciplinary teams. The class meets twice per week: one 50-minute class and one 3-hour laboratory period. This experiment was part of a biomedical theme that was used to introduce engineering principles related to units and conversions, engineering measurements; analysis and representation of data; and modeling using linear, exponential and power law functions.

\section{Background Information}

\subsection{Pedagogical Framework}

The project was conducted in the context of the How People Learn (HPL) framework (Bransford, Brown, and Cocking 1999). HPL has been used extensively in designing university bioengineering modules that enhance learning outcomes (Cordray et al., 2007, Greenberg et al., 2013, Roselli and Brophy, 2006, Vernengo and Dahm, 2012). The HPL framework comprises four pillars: knowledge-centeredness, learner-centeredness, assessment-centeredness, and community-centeredness. A learner-centered approach considers the knowledge, skills, attitudes and beliefs that students bring to their educational experience. A knowledge-centered approach promotes conceptual understanding and organization. An assessment-centered course gives frequent opportunities for constructive formative feedback, and a community-centered environment incorporates collaborative learning in a community of peers. 
The structure of each laboratory was based on the approach described by Linsenmeier et al. (2008) in which the How People Learn (HPL) framework was applied to a human metabolism laboratory. A similar challenge-based approach was used in a sustainability project at our university previously (Farrell 2014a, 2014b). In the drug delivery challenge were asked whether the rate control mechanism of drug from a tablet would change under different drug experimental conditions. Associated with the laboratory experiment was a pre-lab introduction in which students' prior conceptions were uncovered through discussion, and new concepts were connected and built upon this knowledge. The pre-laboratory class session introduced a motivating problem that would be explored during the experiment, helping students to organize their body of knowledge (knowledge-centered); in this case the problem was how to deliver a drug at a controlled rate from a tablet. The assessment-centered leg of the HPL framework was provided by the pre-laboratory quiz as well as lab notebook page reviews. During the prelaboratory session, the in-class discussion provided formative feedback to both the students and the professor. The professor was able to assess students' pre-existing knowledge, disrupt misconceptions and facilitate students' construction of knowledge through linkages between prior knowledge and new concepts. The lab notebook pages were also reviewed by the instructor before the students left the laboratory, and formative feedback was given regarding accuracy and quality of the investigation and analysis. The course was community-centered in the use of inclass breakout groups for brainstorming and discussion, followed by whole-class discussion. Students worked collaboratively in teams of 3 throughout the project, with the team size chosen according to the recommendations set forth by Oakley et al. (2004).

\subsection{Oral Drug Delivery Systems}

Oral drug administration offers many advantages over other routes of administration, for example, patient compliance, convenience, cost-effective manufacturing, and usually a long shelf life of the drug. Conventional, immediate-release formulations such as a liquid solution can offer effective therapy for many drugs administered orally, but not for all drugs. Among the challenges that confront oral delivery of certain drugs are (1) the need for frequent administration to maintain therapeutic effectiveness which often results in decreased patient compliance and/or unsteady pharmacodynamics responses, (2) acid or enzymatic degradation of some compounds in the stomach (3) side effects associated with peak levels of the drug and (4) location-dependent absorption windows within the GI tract. The advent of drug delivery technology has brought 
new options in oral delivery that overcome some of these challenges using novel strategies for spatial and temporal control of drug release to control the bioavailability of the drug. Controlled release delivery forms are designed to release a drug at a predetermined rate by maintaining a therapeutic drug level for a specific period of time. Drug targeting systems aim to deliver a drug preferentially to a desired location in the body to optimize its effectiveness and minimize side effects. The design of oral drug delivery systems optimizes the dosage form characteristics relative to the GI environment, considering aspects such as the physiology and of the GI tract and absorptive properties of the GI mucosa, pharmacokinetic considerations and biopharmaceutical considerations. With oral controlled drug delivery systems, the rate and extent of drug absorption is determined by the rate of release from the dosage form, but the bioavailability (fraction of the administered drug that enters the systemic circulation) is often be lower than in oral controlled release formulations, due to a variety of factors. These factors include, for example, incomplete drug release from the dosage form in the GI tract or increased metabolism in the liver prior to entering systemic circulation (first pass metabolism) when liver metabolism is dose-dependent. More detailed background on oral controlled release delivery is presented in Gupta and Robinson (1992).

Papers on drug delivery topics have begun to appear in the educational literature in recent years. Xu et al. (2010) described the introduction of a drug delivery project in a mass transfer course. Norman et al. (2011) developed a laboratory module focused on diffusion of molecules across skin. Farrell and Hesketh (2002) presented a drug delivery experiment using a lozenge as a dissolving matrix with dissolution rate control, and Farrell and Vernengo (2012) described an experiment using alginate particles in which the mechanism of rate control and release rate are determined by the degree of cross-linking of the alginate. Prausnitz and Bommarius (2011) describe an undergraduate and graduate course on pharmaceutics that includes topics in drug delivery. Our paper adds to the current literature on drug delivery education by presenting a cost-effective, transferrable experiment in which the rate controlling mechanism and release rate of drug from a tablet are determined by the tablet formulation.

\subsection{Swellable Matrix Drug Delivery Systems}

Swellable matrices are monolithic drug delivery systems formed by direct compression of drug and polymer particles. The polymer, drug, and usually other excipients (inert or inactive substances) are uniformly distributed throughout the matrix. A hydrophilic polymer swells when 
exposed to water, forming a gel layer as a result of the transition from glassy to rubbery state. The gel layer acts as a protective film for the matrix core, which is susceptible to erosion. During the drug release process, several regions exist in the swellable matrix (Colombo et al., 2000), as shown in Figure 1.

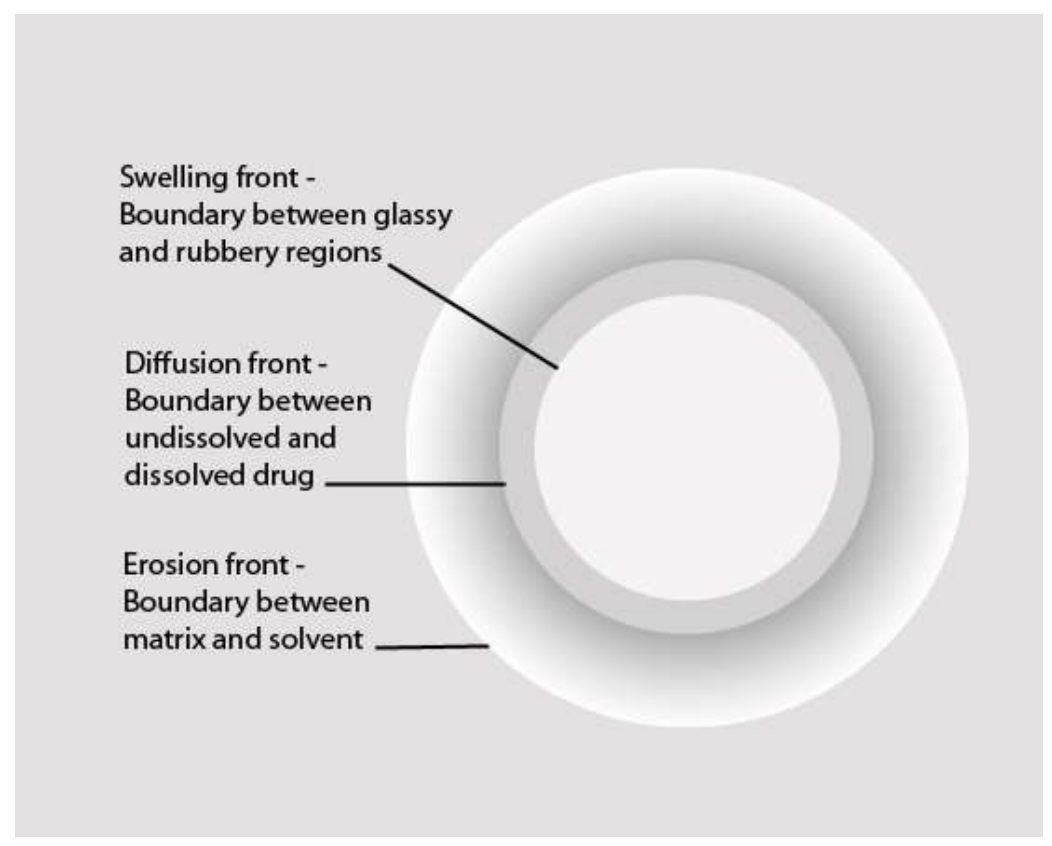

Figure 1. The regions in a swellable matrix. Author's representation of a photograph originally presented in Colombo (2000) in which the swelling, diffusion, and erosion fronts are identified.

The swelling front is the region between the glassy and rubbery regions of the polymer. The diffusion front represents a boundary between undissolved and dissolved drug, with undissolved drug being present in the core of the matrix, and dissolved drug being present toward the outer surface. Near the outer surface is the erosion front, a boundary between the matrix and the surrounding solvent. The thickness of the gel layer is determined by the relative positions of the swelling and erosion fronts. The swelling front moves inward due to water penetration, while the erosion front moves either outward due to swelling or inward due to erosion. The position of the diffusion front is dependent on the drug solubility, loading and the dissolution rate (Colombo et al., 2011).

\subsection{Mass Transfer}

One dimensional diffusion of a drug through a thin slab of thickness $1 / 2$ and diffusion coefficient $\mathrm{D}$ is described by Fick's second law,

$$
\frac{\partial C}{\partial t}=D \frac{\partial^{2} C}{\partial x^{2}}
$$


When the system is initially at uniform drug concentration $\mathrm{C}_{1}$, and the surfaces are maintained at a constant drug concentration $\mathrm{C}_{0}$, the boundary conditions are

$$
\begin{array}{lll}
t=0 & C=C_{1} & -l / 2<x<l / 2 \\
t>0 & C=C_{0} & x= \pm l / 2
\end{array}
$$

The solution to this equation (Crank 1975) is

$$
\frac{M_{t}}{M_{\infty}}=4 \frac{(D t)^{1 / 2}}{l^{2}}\left[\frac{1}{\pi^{1 / 2}}+2 \sum_{n=1}^{\infty}(-1)^{n} \operatorname{ierfc} \frac{n l}{2(D t)^{1 / 2}}\right]
$$

At short times, the ierfc term approaches zero, and a short-time approximation is:

$$
\frac{M_{t}}{M_{\infty}}=4\left[\frac{D t}{\pi l^{2}}\right]^{1 / 2}
$$

This approximation is valid for the first $60 \%$ of drug released $\left(M_{t} / M_{\infty}=0.60\right)$ (Ritger and Peppas 1987a).

The rate of release of a drug from a polymeric device can be controlled by Fickian diffusion through the polymer matrix (Ritger and Peppas, 1987a) or by polymer relaxation in the case of a swellable polymer (Ritger and Peppas, 1987b). Korsmeyer et al. (1983) present a simple model for drug release from a polymer which can be used to identify the mechanism of rate control, shown as Equation (4)

$$
\boldsymbol{F}=\frac{M_{t}}{M}=k t^{n}
$$

where $M_{t}$ is the mass of drug released at time $t, M_{\infty}$ is the mass of drug released after infinite time, $F$ is the fraction released, $k$ is a constant that depends on the diffusion coefficient and diffusion length, and $n$ is an exponent which is indicative of the rate control mechanism. For Fickian diffusion in a slab, $n=0.5$, as in Equation (3). Diffusion of drug molecules through the matrix depends on the size of the drug molecules and the spaces available for diffusion. It is important to note that this short-time approximation is valid for $M_{t} / M_{\infty} \leq 0.6$.

When the polymer is swellable, polymer relaxation, in addition to diffusion, may govern the release rate (Ritger and Peppas 1987b; Peppas and Sahlin, 1989). Relaxation, or swellingcontrolled delivery systems are devices that control drug release by a polymer morphology change through interaction with the release medium. Drug incorporated in this type of system cannot diffuse to any significant extent in the initial form, but is able to diffuse once the polymer chains become more flexible as the result of contact with the medium. For relaxation control, $n$ $=1.0$ for a slab. When $\mathrm{n}$ lies between the values for Fickian diffusion and relaxation control, 
both diffusion and relaxation contribute to rate control. It is important to note that the values of $0.5<\mathrm{n}<1.0$ are valid for a thin slab. Modeling of drug release from cylindrical and spherical geometries results in different values of $\mathrm{n}$, as described by Ritger and Peppas (1987a, 1987b).

The normalized release rate, $\frac{d F}{d T}$, can be found by differentiating Equation (4):

$$
\frac{d F}{d T}=k n t^{n-1}
$$

When the release rate is governed by diffusion control, important variables include drug loading, drug solubility in the matrix, drug dissolution rate in the matrix, and drug diffusivity in the matrix. The rate of water penetration, rate of polymer erosion or dissolution, and hydrodynamic conditions are important factors in erosion control. Swelling control is achieved when the concentration gradient of the drug in the swelled region controls the release rate. Due to chain relaxation, drug transport may occur by convection in addition to diffusion. More than one mechanism of release may be present, in which case the relative rates of all the processes are important.

\subsection{Caffeine}

Caffeine is chosen as a model drug in this experiment, for its moderate solubility in water, ease of analysis by UV spectrophotometry, and its low toxicity. Caffeine is an organic white powder with the molecular formula $\mathrm{C}_{8} \mathrm{H}_{10} \mathrm{~N}_{4} \mathrm{O}_{2}$. Caffeine is commonly found in foods such as coffee, tea, soda and cocoa, and its effect as a mild central nervous system (CNS) stimulant is familiar to most of us. In the medical world, caffeine is known as trimethylxanthine, and is generally used as a cardiac stimulant, although it is normally thought of as an energy stimulant. A cup of fresh coffee contains between 0.00008 and $0.00035 \mathrm{~kg}$ of caffeine (NSW 2002). The caffeine tablets made in this lab contain between $0.00012-0.00036 \mathrm{~kg}$ of caffeine.

\subsection{Excipients}

In addition to an active pharmaceutical ingredient (API), tablets are formulated with a number of biologically inert materials known as excipients. Excipients perform certain functions such as providing processing and compression characteristics (binders, diluents, glidants, and lubricants) or other characteristics such as color and flavor. While excipients are biologically inert, they do influence the stability and bioavailability of the drug as well as the design of the process for dosage form preparation. Binders are used to impart cohesive properties to the tablet to ensure that it remains intact after compression. When the therapeutic dose of an API is very 
small, a diluent is added to the formulation to make the tablet a practical size. Lubricants serve multiple functions in tablet production. They increase flowability of the granular formulation, prevent adhesion of material to the die and punch and facilitate tablet ejection from the die. Glidants are added just before compression to improve the flow characteristics of a powder formulation. Controlled release formulations use polymers or waxes to slow the release of the drug using different rate controlling mechanisms. The excipients used in the formulation of the caffeine tablets in this experiment are lactose (filler and binder), magnesium stearate (lubricant) and POLYOX ${ }^{\mathrm{TM}}$ (controlled release).

POLYOX ${ }^{\mathrm{TM}}$ water-soluble resins are non-ionic, high molecular weight water-soluble polyethylene oxide (PEO) polymers that hydrate quickly and are available in a wide range of molecular weights (Dow Chemical Company, 2002). Granular grades of PEO possess certain characteristics that are necessary for the preparation of solid dosage forms: it is free flowing, lubricated, and has sufficient cohesiveness to ensure that the compressed tablet will remain intact (Dhawan et al., 2005). Two POLYOX ${ }^{\mathrm{TM}}$ resins were used in this experiment: POLYOX ${ }^{\mathrm{TM}} \mathrm{N}-$ 10 (MW 100,000) and POLYOX 303 (MW 7 Million).

Lactose is a beneficial excipient because it acts as a soluble diluent that adds bulk to powders, and a binder that improve cohesiveness of the formulation. It is also inert, innocuous and inexpensive. The average particle size for spray dried lactose is $100 \mu \mathrm{m}$, which is large even when compared to other bulk fillers of $70-90 \mu \mathrm{m}$ (Levina, 2004). It also allows the particles to mix together well when being compressed into a tablet. The large pore diameter of lactose pellets increases the crushing strength of the tablet as well as the available surface area. The hydrophilicity of lactose may also increase water uptake into the tablet. However, changes in $\mathrm{pH}$ cause the pore diameter of lactose to decrease and consequently slow drug release (Costa, 2004).

Magnesium stearate serves as a lubricant in the tablet formulation. Magnesium stearate is one of the most commonly used lubricants, and like most lubricants it is used in low concentrations because its hydrophobic nature can slow disintegration and dissolution of the tablet. However, in addition to acting as a lubricant, magnesium stearate decreases interparticle bonding. This results in a lower tensile strength of the tablet due to a greater propensity for stress relaxation which allows for increased porosity expansion after compression (Zuurman et al., 1999). 


\section{The Tablet Experiment}

\subsection{Objectives}

In this experiment, students produce drug-containing compressed polymer tablets and investigate the factors that affect the rate of release of the drug from the tablets. The model drug used in this experiment is caffeine, a drug with moderate water solubility. Each team produced a tablet using an assigned formulation from 
Table 1. Drug release studies are performed by placing the drug-loaded tablet in a beaker containing water and monitoring concentration as a function of time. Concentration measurements are made periodically by measuring absorbance of the surrounding solution (into which drug has been released) using a spectrophotometer. At the end of the experiment, teams shared experimental data with one another. The release rate of the drug from the tablets is analyzed using Excel. Through comparison to the mathematical model, the mechanism of rate control can be identified. Students investigate the effect of drug loading, polymer composition, and polymer molecular weight on the release rate of the drug and the mechanism of rate control. Expected skills and measurable outcomes are summarized in Table 3 in the Evaluation section.

\subsection{Tablet Preparation \\ Materials}

Caffeine (Reagent Plus), magnesium stearate (puriss), and lactose (Ph Eur) were obtained from Sigma Aldrich. POLYOX ${ }^{\mathrm{TM}}$ was obtained from Colorcon (West Point, PA).

\subsubsection{Procedure}

A tablet formulation was chosen from 
Table 1. The excipients and the caffeine were weighed and placed in a Ziploc ${ }^{\circledR}$ snack bag, and the powder was dry-blended by shaking and rotating for several minutes. Tablets were pressed with a single punch Carver Mini-C Press in a $0.018 \mathrm{~m}$ diameter die with compression at a force of 2 metric tons; instructions should be given to attempt to standardize the compression time. (While technically too large for oral administration, a tablet this size provided measureable absorbance values in the spectrophotometer.) The tablet press is shown in Figure 2. The tablet press costs about $\$ 2,600$ if purchased new; however, single punch tablet presses in good condition can be found on ebay in the $\$ 1,000-\$ 1,200$ range. 
Table 1. Tablet formulations used in the experiments

\begin{tabular}{lllll}
\hline Mass x 10 $^{\mathbf{3}}(\mathbf{k g})$ & $\mathbf{A}$ & $\mathbf{B}$ & $\mathbf{C}$ & $\mathbf{D}$ \\
\hline \hline Caffeine & 0.12 & 0.24 & 0.36 & 0.24 \\
\hline POLYOX $^{\mathrm{TM}}$ & 0.24 & 0.24 & 0.24 & 0.12 \\
\hline Lactose & 0.828 & 0.708 & 0.588 & 0.828 \\
\hline Magnesium Stearate & 0.012 & 0.012 & 0.012 & 0.012 \\
\hline
\end{tabular}

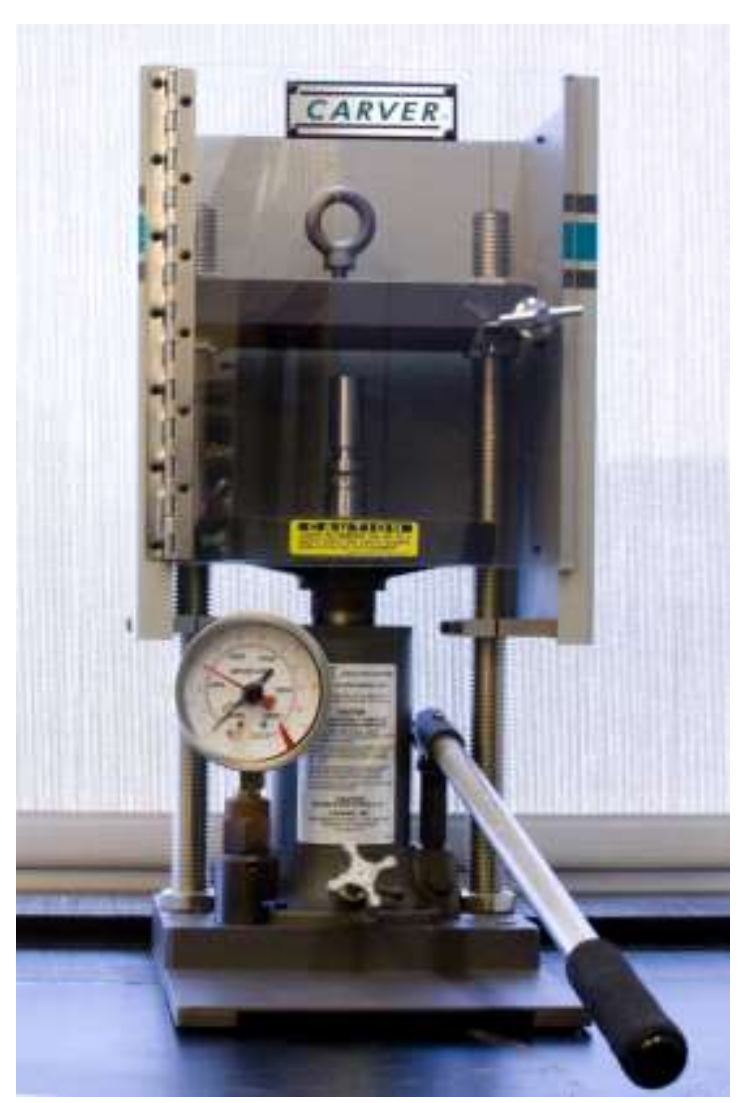

Figure 2. Carver Mini C Tablet Press

\subsection{Caffeine Release Study}

\subsubsection{Materials}

The caffeine release study used the following standard laboratory materials: a magnetic stirring plate and stir bar, a 2 L beaker, a dropping pipette, a quartz cuvette, and a stopwatch. A caffeine tablet and distilled water were also required. A tea infuser was used as a basket to suspend the tablet in the beaker. Readily available supplies were used in this practical and economical setup. A USP dissolution apparatus typically required for drug release experiments 
in a research lab would have rendered the experiment prohibitively expensive for a first year engineering course in which multiple teams work simultaneously.

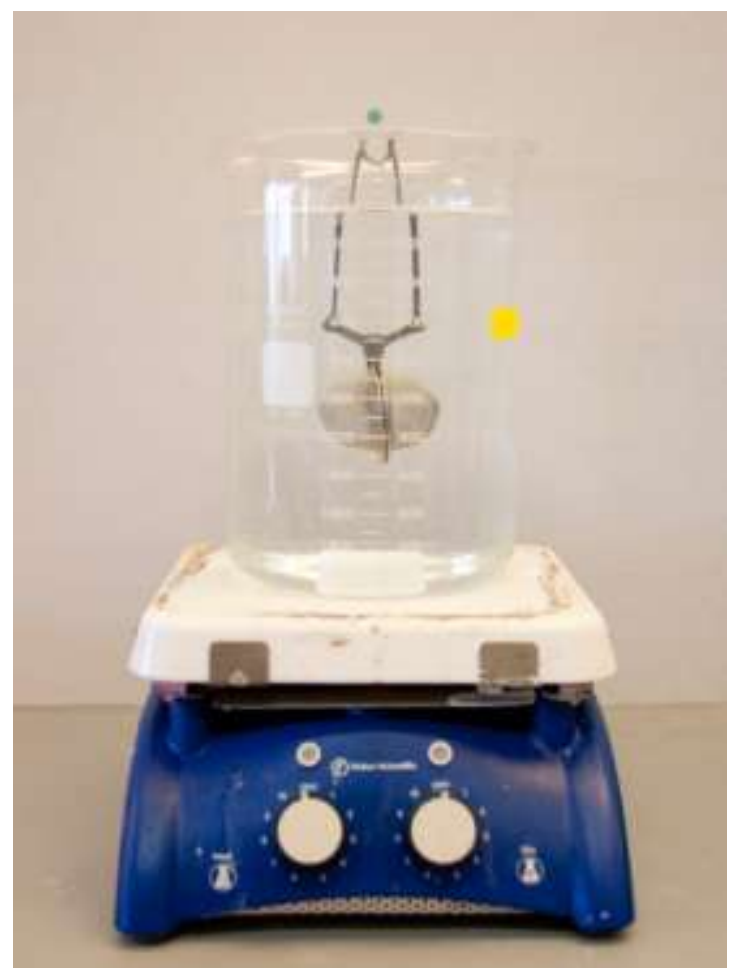

Figure 3. The experimental setup for the drug release study

\subsubsection{Procedure}

A $2 \mathrm{~L}$ beaker was filled with $2 \mathrm{~L}$ distilled water; this was placed on a magnetic stir plate, and a stir rate of $60 \mathrm{rpm}$ was achieved using a magnetic stir bar. A caffeine tablet was placed in the tea infuser, and the infuser was suspended about $0.01 \mathrm{~m}$ above the stir bar. A stopwatch was used for timing, and $0.001 \mathrm{~L}$ samples were taken every five to ten minutes. The sample was placed in a UV-transparent cuvette, and the absorbance was measured using a Spectronic 21 spectrophotometer at a wavelength of $273 \mathrm{~nm}$. The aliquots withdrawn for analysis were replaced with an equal volume of dissolution medium (distilled water) to maintain a constant volume. For the freshman course, the experiment was run for 2-3hours. The experimental setup is shown in Figure 3.

\subsection{Analysis of Results}

After the experiment was completed, the students used an Excel spreadsheet for data analysis. The students converted the recorded absorbance measurements into concentration 
values using the provided equation from the calibration curve given in Figure 4. To save time during the laboratory period, calibration data were provided with the lab instructions.

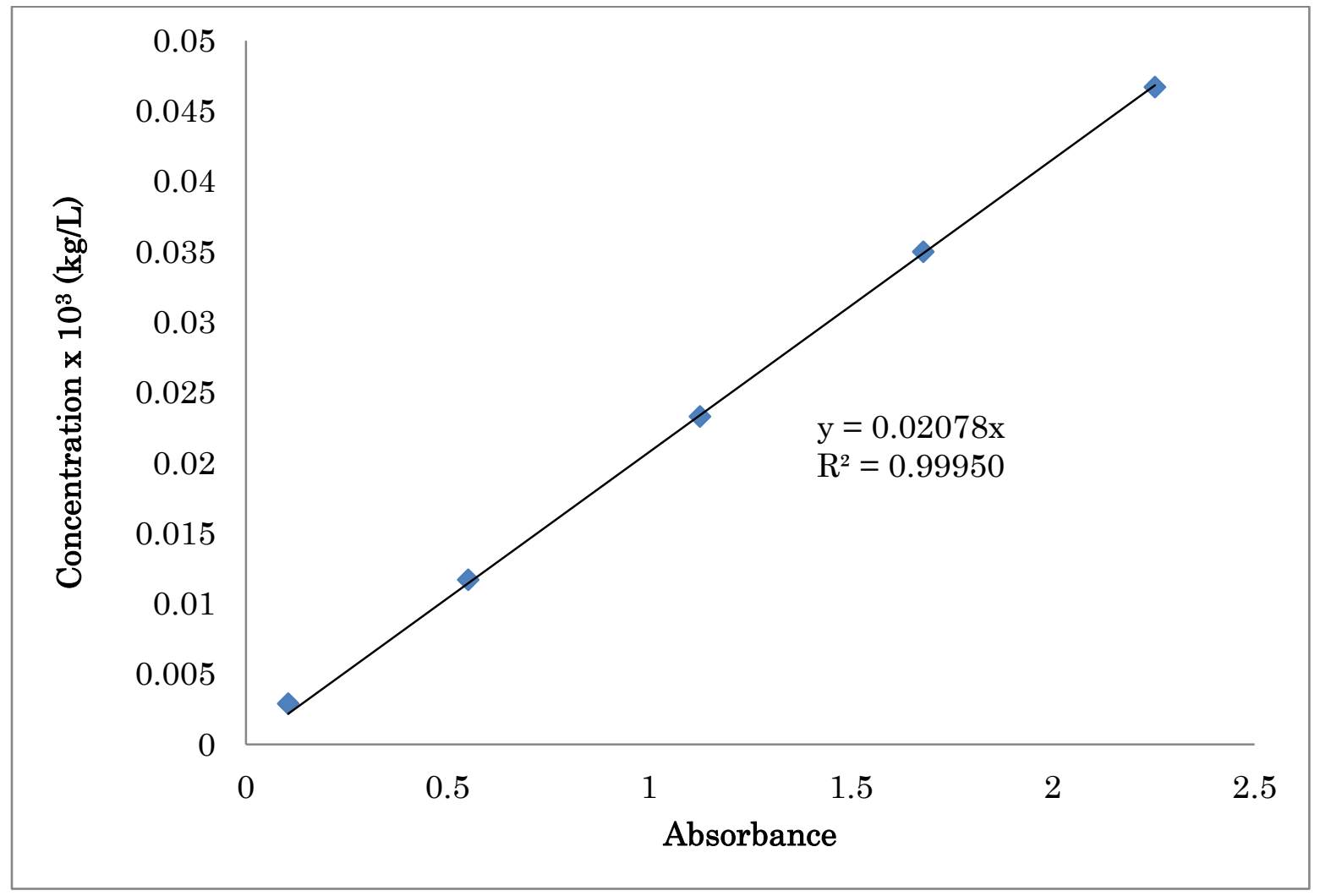

Figure 4. Caffeine calibration curve at $273 \mathrm{~nm}$.

Students set up an Excel spreadsheet to calculate the following quantities at each sample time: Concentration of caffeine in solution $(C)$, mass of caffeine released $\left(M_{t}\right)$, and fraction of caffeine released $(F)$. The concentration was determined from the calibration equation:

$$
C=0.0208 A
$$

The mass of caffeine released was determined from the concentration and volume $(V)$ measurements.

$$
M_{t}=C V
$$

Infinite time is considered to be when the absorbance of the sample ceases to increase over successive measurements, indicating that the release rate of the drug approaches zero. To simplify the procedure for the students, the value of $\mathrm{M}_{\infty}$ was approximated as $\mathrm{M}_{0}$ in the calculation of $\mathrm{F}$ since the value of $\mathrm{M}_{0} / \mathrm{V}$ is less than $1 \%$ of the solubility of caffeine in water. It 
should be noted that the class period was considerably shorter than "infinite time" in most cases; however it should also be remembered that the model used is valid for short times.

After converting the measured absorbance values to fraction of drug released, the students created a plot showing the fraction of drug released over the time of the experiment. Students were asked to predict how different factors would affect the release rate: drug loading, polymer molecular weight, drug molecular weight, stirring rate, temperature, etc. Several of these factors were investigated experimentally by teams using shared data.

Taking the natural log of both sides of Equation (4), a plot of the natural log of fraction released vs. natural log of time will result in a straight line with a slope of $n$. The value of $n$ is used to identify the rate controlling mechanism as explained above. The release rate is calculated from Equation (5) and plotted as a function of time.

\section{Results from Student Experiments}

The results below show the effect of drug loading, polymer composition, and polymer molecular weight on the release profile and the mechanism of rate control. These effects can be elucidated using data for the 2-3-hour time frame of our freshman experiments. Data points represent the mean of measurements performed in triplicate on single samples. Again, the assumption of one dimensional diffusion in a thin slab is an approximation which is based on the minimum diameter-to-thickness aspect ratio of 6 , at the center of the tablet). Plots of $\ln (\mathrm{F}) \mathrm{vs}$. $\ln (\mathrm{t})$ are presented for values of $\mathrm{F}<0.6$.

\subsection{Effect of Drug Loading}

Figure 5 shows the effect of drug loading on the release profile of caffeine from the tablet. A loading of $30 \%$ of the total tablet mass results in a faster release rate than $10 \%$ caffeine due to the larger driving force for diffusion. When the drug loading increases from $10 \%$ to $30 \%$, the value of $n$ changes from $0.668 \pm 0.024$ to $0.649 \pm 0.017$, as shown in Figure 6 . This indicates that the loading of caffeine is not important in determining the rate control. Caffeine is a moderately soluble drug with a solubility of $16 \mathrm{~kg} / \mathrm{m}^{3}$, and the diffusion of water into the matrices is not greatly augmented by the drug but rather by the lactose composition which is larger for Formulation A. 


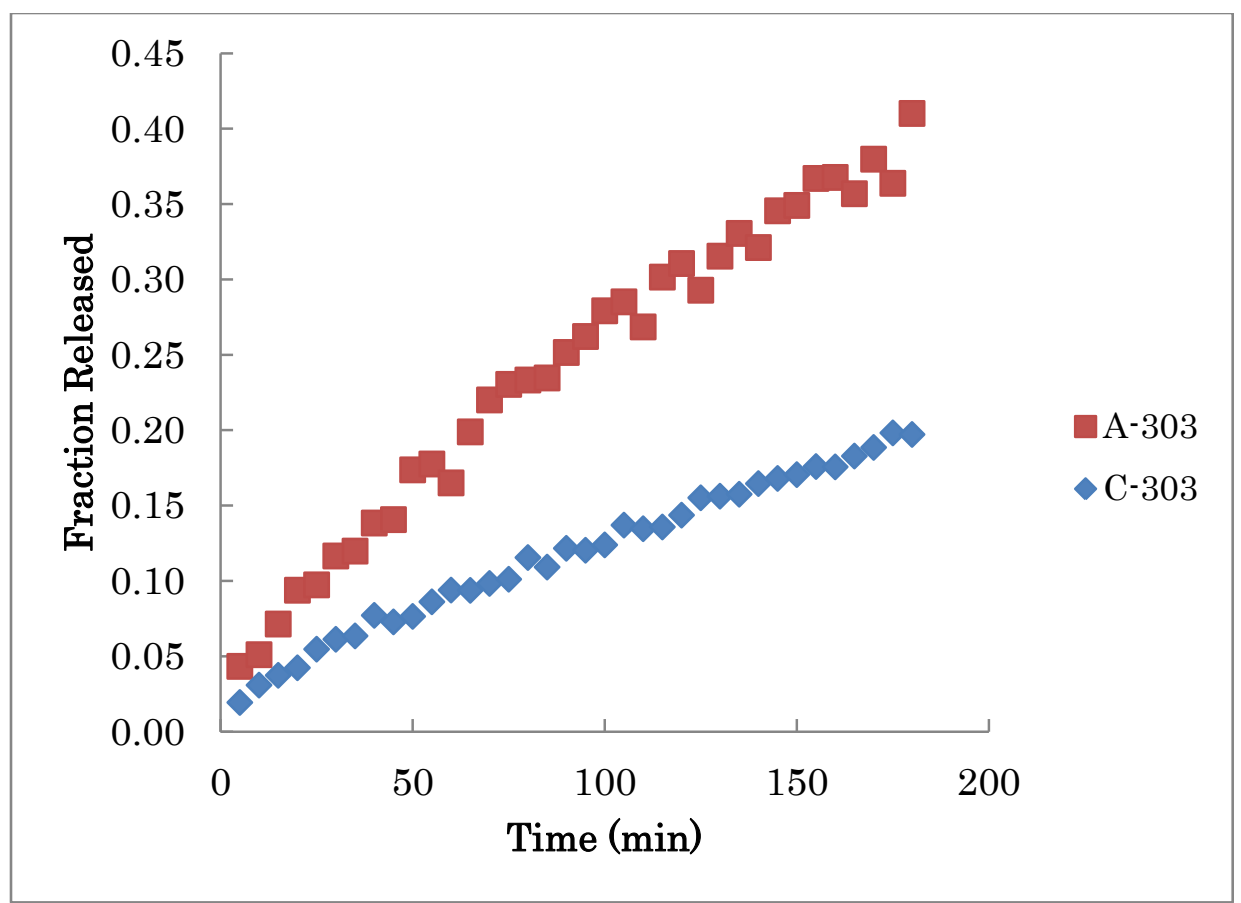

Figure 5. Effect of drug loading on release profile. Polymer composition $20 \% \mathrm{POLYOX}^{\mathrm{TM}} 303$. $10 \%$ Caffeine (Formulation A) and 30\% Caffeine (Formulation C) 


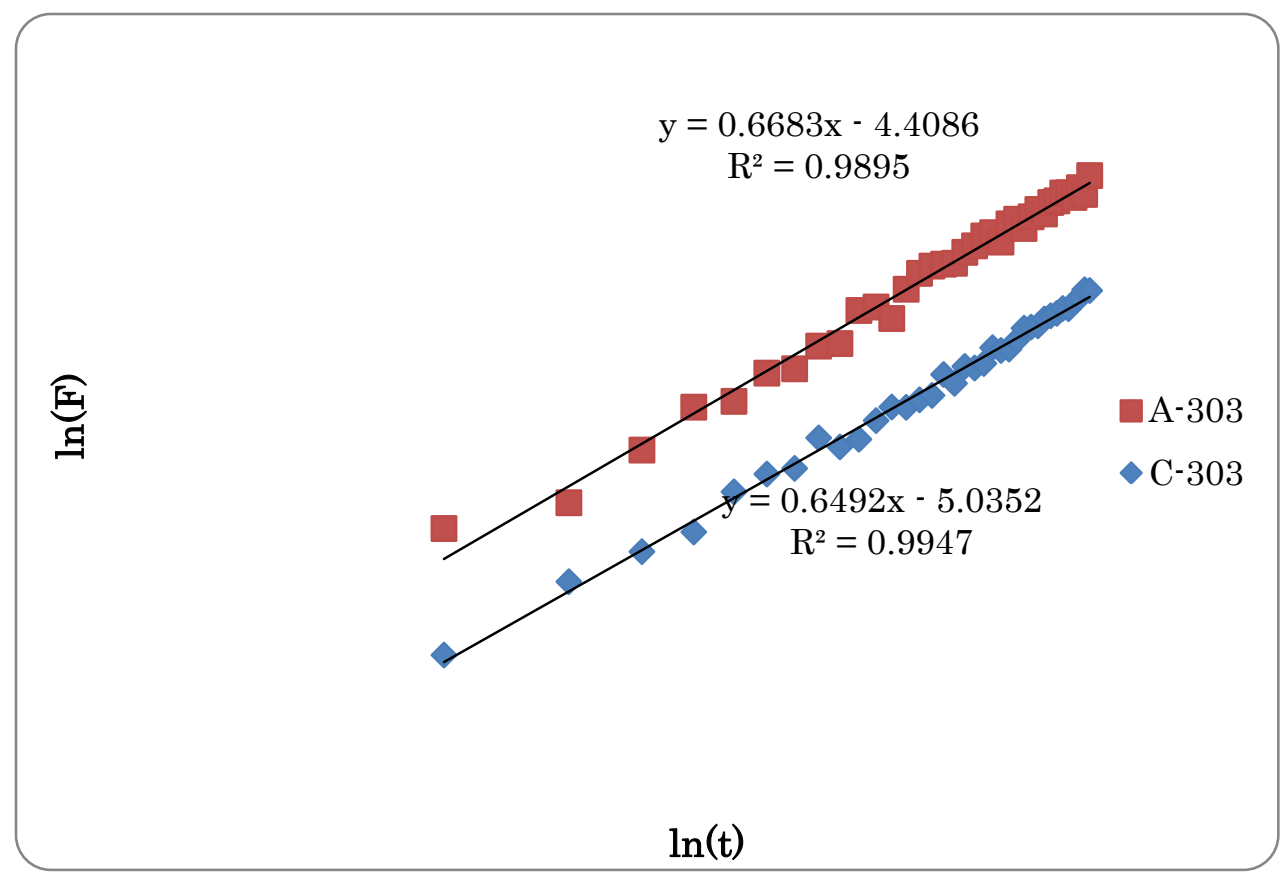

Figure 6. Effect of drug loading on release mechanism. Polymer composition $20 \%$ POLYOX ${ }^{\mathrm{TM}}$ 303. $10 \%$ Caffeine (Formulation A) and 30\% Caffeine (Formulation C)

\subsection{Effect of Polymer Composition}

Figure 7 shows a comparison of Formulations B and D, having 20\% and 10\% w/w polymer composition respectively. 20\% $\mathrm{POLYOX}^{\mathrm{TM}}$ results in slower release than the $10 \%$ POLYOX ${ }^{\mathrm{TM}}$ formulation. This may be attributed to the increased viscosity of the gel layer with the higher polymer composition. The effect of Polyox composition on the release mechanism is shown in Figure 8. With $10 \%$ POLYOX $^{\mathrm{TM}}$, the gel layer is less viscous and diffusion occurs more freely $(\mathrm{n}=0.518 \pm 0.018)$. Increasing the polymer composition to $20 \% \mathrm{POLYOX}^{\mathrm{TM}}$ increases the viscosity of the gel and the extent of swelling and results in an increase in the contribution of swelling to the kinetics $(n=0.625 \pm 0.023)$. With $20 \%$ POLYOX $^{\mathrm{TM}}$, anomalous kinetics with contributions from diffusion and swelling are observed. When comparing Formulations $\mathrm{B}$ and $\mathrm{D}$, one must also consider that the higher lactose composition in Formulation D may result in greater water penetration and contribute to a faster release rate. 


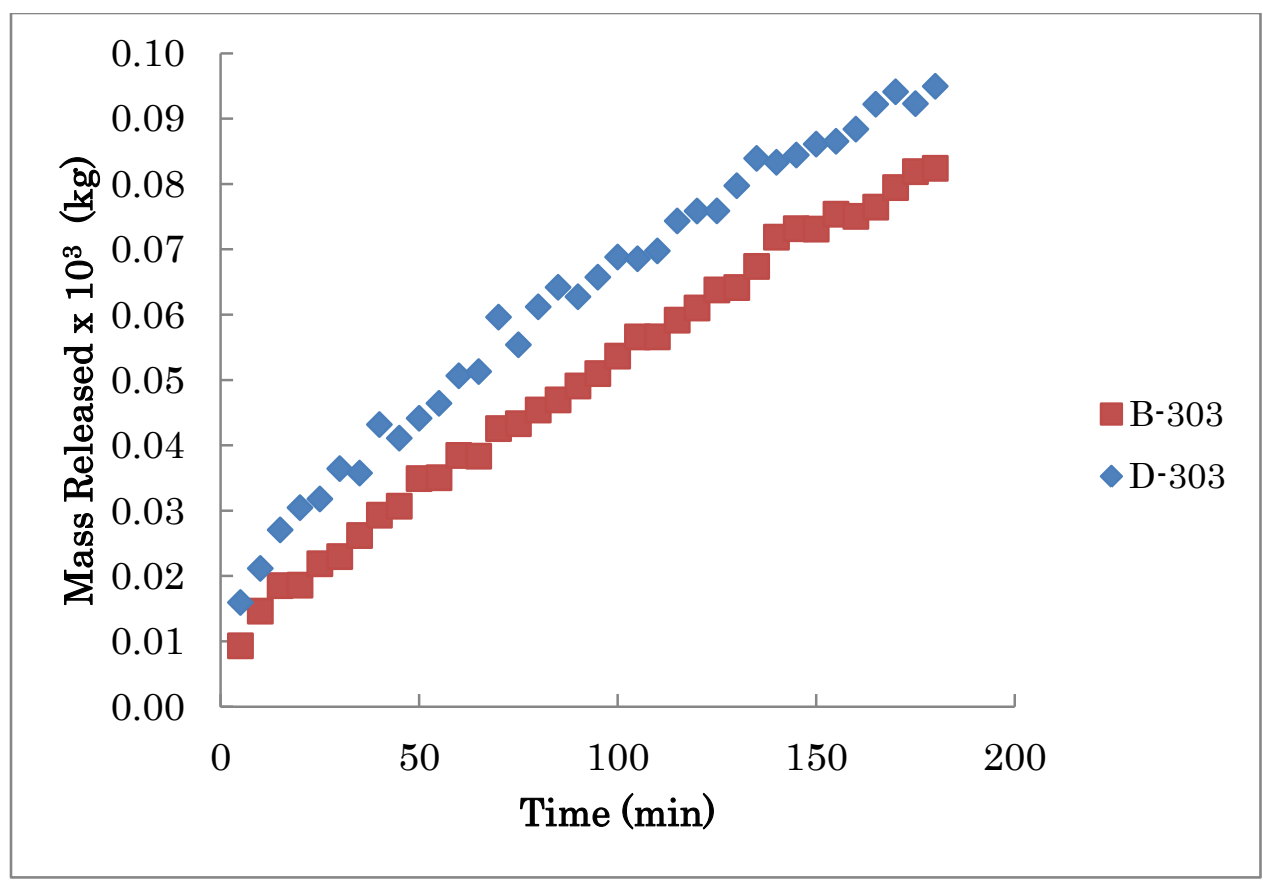

Figure 7. Effect of Polyox 303 composition on release profile. Drug loading $20 \%$ caffeine. $10 \%$ Polyox (Forumlation D) and 20\% Polyox (Formulation B).

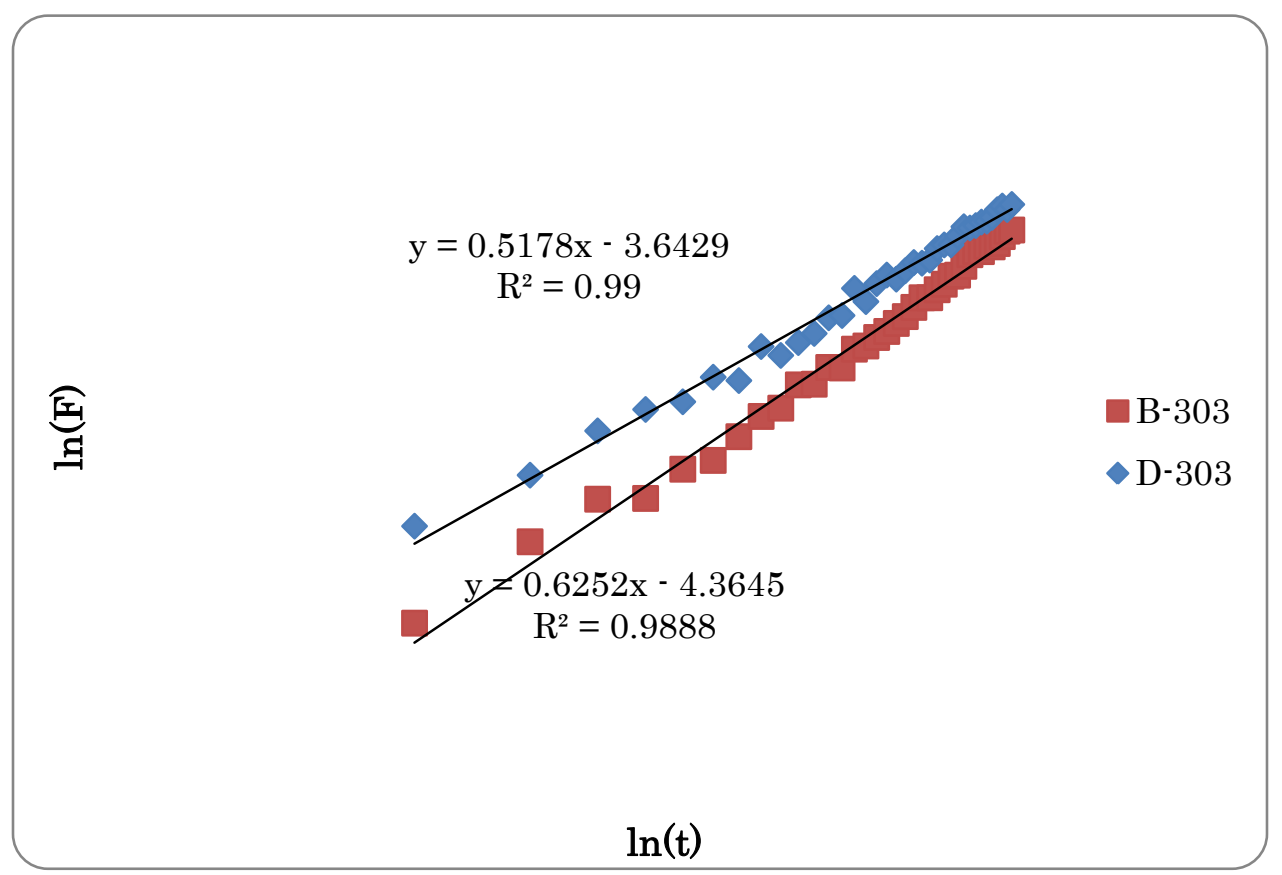

Figure 8. Effect of polymer composition on release mechanism. Drug loading $20 \%$ caffeine. $10 \%$ Polyox (Forumlation D) and 20\% Polyox (Formulation B). 


\subsection{Effect of Polymer Molecular Weight}

The lower molecular weight polymer POLYOX ${ }^{\mathrm{TM}} \mathrm{N}-10$ releases drug at a faster rate than higher molecular weight POLYOX ${ }^{\mathrm{TM}} 303$ due to more rapid diffusion of drug through the gel layer, as shown in Figure 9. The lower molecular weight polymer POLYOX ${ }^{\mathrm{TM}} \mathrm{N}-10$ has a higher diffusional exponent $(\mathrm{n}=0.726 \pm 0.037)$ in comparison with the higher molecular weight POLYOX $^{\mathrm{TM}} 303(\mathrm{n}=0.668 \pm 0.024)$. As the molecular weight increases, the erosion rate of the polymer decreases faster than the swelling rate decreases. Thus the gel layer thickness increases more rapidly in the higher molecular weight polymer, as reflected by the lower value of $\mathrm{n}$ which indicates a greater contribution of Fickian diffusion toward the release kinetics in the higher molecular weight polymer. This is consistent with the findings of Kim (1995) for theophylline release from poly(ethylene oxide) tablets. 


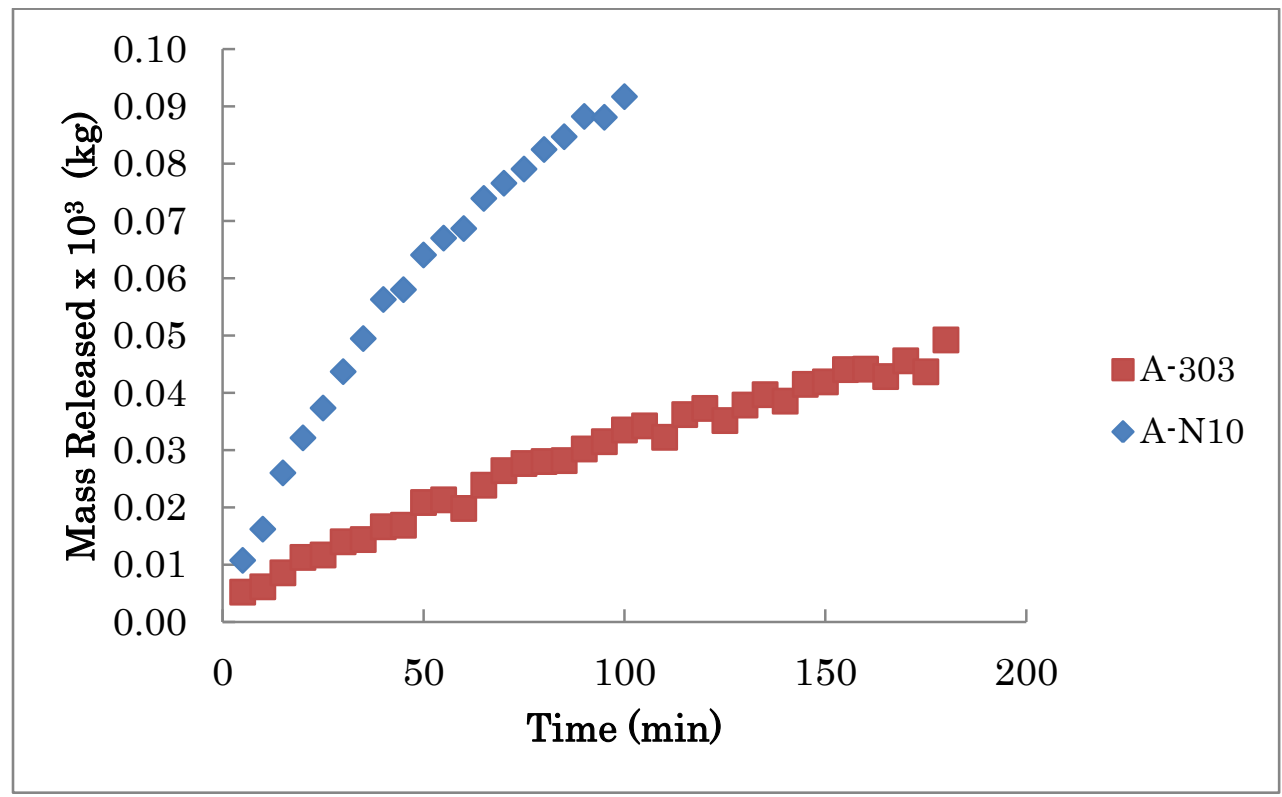

Figure 9. Effect of polymer molecular weight on release profile. Drug loading $10 \%$ caffeine. $20 \%$ POLYOX $^{\mathrm{TM}}$ (Formulation A)

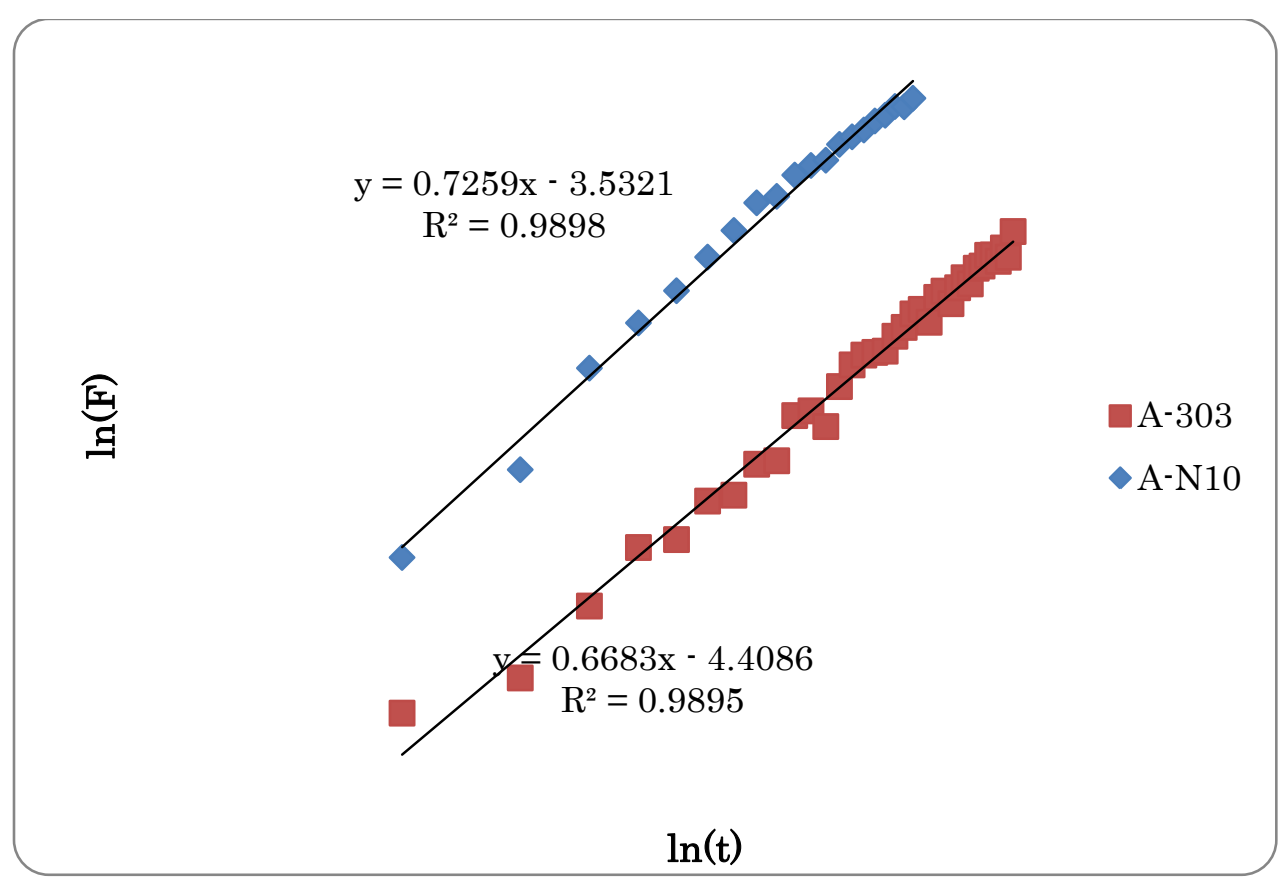

Figure 10. Effect of polymer molecular weight on release mechanism. Drug loading $10 \%$ caffeine. $20 \%$ POLYOX $^{\mathrm{TM}}$ (Formulation A) 


\subsection{Rate Release Profiles}

Using the values of $\mathrm{k}$ and $\mathrm{n}$ that were obtained from Figure 6, Figure 8, and Figure 10 for each tablet formulation, the release rate is calculated from Equation (5). The release rates of caffeine from each tablet formulation are shown in Figure 11. Comparing formulations A and C, it is evident that the higher drug loading of formulation $\mathrm{C}$ results in a faster release rate.

Comparing formulations $\mathrm{B}$ and $\mathrm{D}$, a larger release rate is observed initially for formulation $\mathrm{D}$ with the lower polymer composition, but at longer times the release rates for the two formulations are equal. Comparing formulation A using POLYOX ${ }^{\mathrm{TM}} 303$ and POLYOX ${ }^{\mathrm{TM}} \mathrm{N}-$ 10, higher molecular weight of POLYOX ${ }^{\mathrm{TM}} 303$ results in a slower release rate than POLYOX ${ }^{\mathrm{TM}}$ $\mathrm{N}-10$.

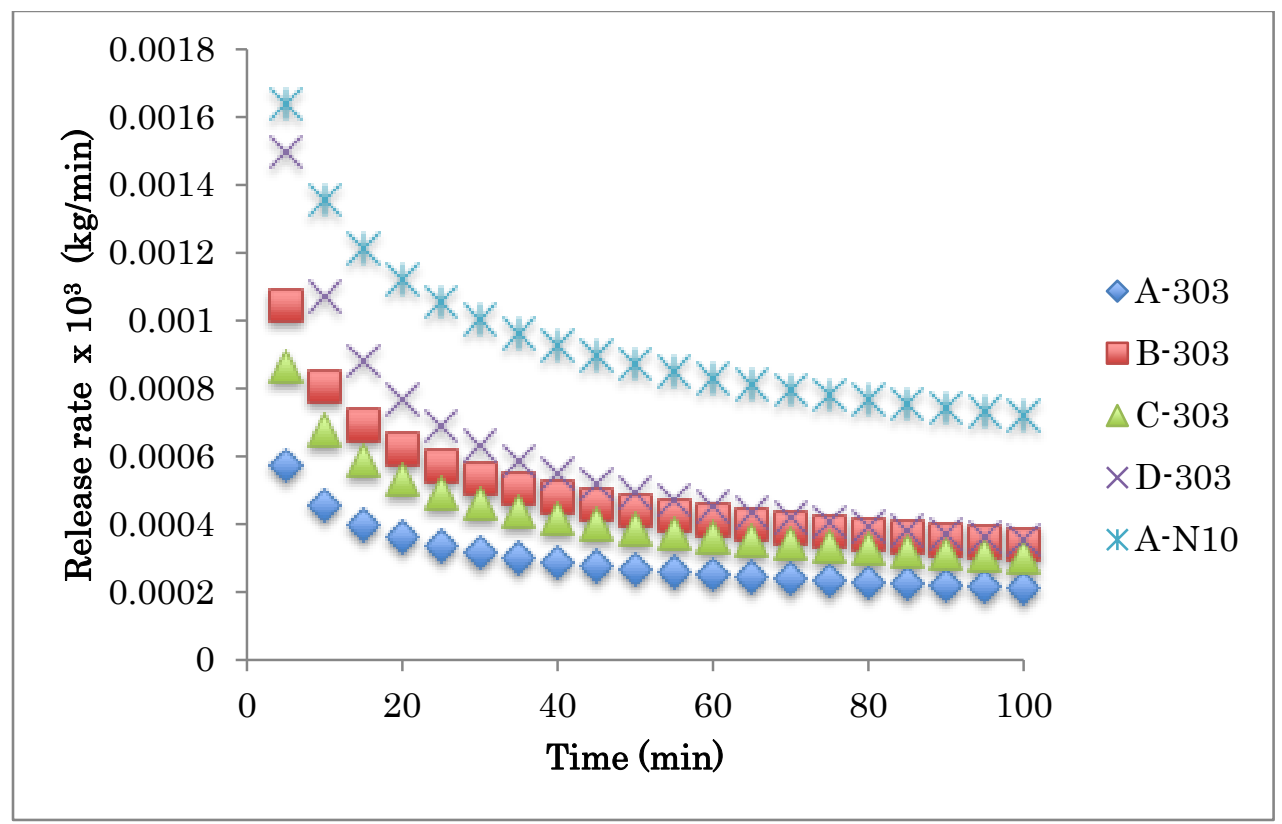

Figure 11. Release rates of caffeine from each tablet formulation.

\section{Evaluation}

Each team completed an assignment that required them to prepare two plots (1) the mass of caffeine as a function of time and (2) a log-log plot of fraction released as a function of time. The slope of the second plot provided the power-law exponent that reveals the mechanism of 
release. The assignment also required students to explore how the rate control depended on the polymer molecular weight, caffeine loading, and polymer composition. Because the team assignment reflected the shared understanding that was built by the team, a short pre-test and post-test were used to evaluate individual knowledge and conceptual gains. A pre-test was administered at the beginning of the pre-lab discussion, and the post-test was conducted after the assignment was submitted. The quiz comprised 8 multiple choice questions which were mapped to course and lab objectives and ABET objectives. An example of a multiple choice question is:

The rate of release from a diffusion-controlled matrix system is
a) Constant with respect to time
b) Proportional to the square root of time
c) Proportional to the drug concentration in the body
d) Proportional to the mass of the tablet

The quiz questions covered topics of diffusion, release kinetics, release mechanism, bioactive compounds, excipients, and equipment. The questions were designed to evaluate whether the experiment was effective in introducing basic principles of drug delivery; reinforcing concepts of science, math and engineering; and teaching skills of data analysis and representation. A summary of the quiz questions is provided in Table 2 in which multiple choice questions are presented as correct statements for brevity.

Table 2. Pre- and Post-module questions presented as correct statements. The bold font indicates the choice that correctly completes each statement.

\begin{tabular}{|c|c|}
\hline $\begin{array}{c}\text { Question } \\
\#\end{array}$ & Correct Statement \\
\hline 1 & The rate of release from a diffusion-controlled matrix system is proportional to the square root of time \\
\hline 2 & $\begin{array}{l}\text { Factors influencing the rate of release from a matrix system are the drug diffusivity in the polymer } \\
\text { matrix and the loading of the drug in the polymer. }\end{array}$ \\
\hline 3 & Caffeine is a central nervous stimulant. \\
\hline 4 & $\begin{array}{c}\text { Brewed coffee contains the highest concentration of caffeine (in comparison with black tea, green tea } \\
\text { and Coca Cola). }\end{array}$ \\
\hline 5 & Lactose is commonly used in tablets as a filler. \\
\hline 6 & Magnesium stearate is commonly used in tablets as a lubricant. \\
\hline 7 & The tablet die has four parts. The pressure gauge is not a part of the die \\
\hline 8 & $\begin{array}{l}\text { When measuring the drug release from a diffusion-controlled matrix tablet, a plot of mass of drug } \\
\text { released vs. time }{ }^{1 / 2} \text { should be linear. }\end{array}$ \\
\hline
\end{tabular}


Questions were mapped to Rowan Engineering Clinic II course objectives and ABET outcomes as shown in

Table 3. This Table also shows the measurable skills that are associated with each outcome. The average score on the pre-test was $32 \%+/-9.5 \%$ for $n=17$ students, and the average score on the post-test was $76 \%+/-1.6 \%$ for $n=18$ students, where the margin of error is the $95 \%$ confidence interval. Students' knowledge related to drug delivery from swellable tablets increased significantly $\left(\mathrm{p}<1 \times 10^{-5}\right)$ after completing the module. The class average normalized gain, defined as the average gain divided by the maximum possible average gain, was $65 \%$. For each outcome listed in

Table 3 the average percentage of correct responses increased between $48-60 \%$ between the pretest and the post-test, as shown in Figure 12.

Table 3. Pre- and post-module assessment questions alignment to: ABET standards for undergraduate chemical engineering students and Rowan University Engineering Clinic II objectives.

\begin{tabular}{|c|c|c|}
\hline Outcome & $\begin{array}{l}\text { Measurable skills categorized within this } \\
\text { outcome: }\end{array}$ & $\begin{array}{c}\text { Pre- and post-test } \\
\text { questions }\end{array}$ \\
\hline $\begin{array}{l}\text { Introduce students to the science and art of } \\
\text { design by evaluating the work of practicing } \\
\text { designers } \\
\text { (Rowan 1) }\end{array}$ & $\begin{array}{l}\text { To indentify how tablet-based drug delivery } \\
\text { systems are manufactured and how they work; } \\
\text { how to measure drug release from tablets; } \\
\text { connect engineering principles to the design of } \\
\text { these particulate systems }\end{array}$ & $1-3,5,6-8$ \\
\hline $\begin{array}{l}\text { Introduce multidisciplinary teams of } \\
\text { engineers to science principles such as } \\
\text { mass balances, transport, and materials } \\
\text { (Rowan 2) }\end{array}$ & $\begin{array}{l}\text { Identify variables that drive mass transfer from } \\
\text { tablets; indentify the role of different } \\
\text { components in tablet design; application of a } \\
\text { mathematical model for predicting release from } \\
\text { such systems }\end{array}$ & $2,5,6,8$ \\
\hline $\begin{array}{l}\text { An ability to apply knowledge of } \\
\text { mathematics, science, and engineering } \\
\text { (ABET-A) }\end{array}$ & $\begin{array}{l}\text { Successfully apply fundamental concepts of } \\
\text { chemistry, material science, and transport } \\
\text { phenomena to tablet delivery systems; Compare } \\
\text { drug dosages and pharmacologic action }\end{array}$ & $1,2,8$ \\
\hline $\begin{array}{l}\text { An ability to design and conduct } \\
\text { experiments, as well as to analyze and } \\
\text { interpret data (ABET-B) }\end{array}$ & $\begin{array}{c}\text { Experience with the preparation and } \\
\text { characterization of particulate drug delivery } \\
\text { system will provide experience in identifying } \\
\text { key variables, analyze data, and evaluate its } \\
\text { significance. }\end{array}$ & $1,2,8$ \\
\hline
\end{tabular}




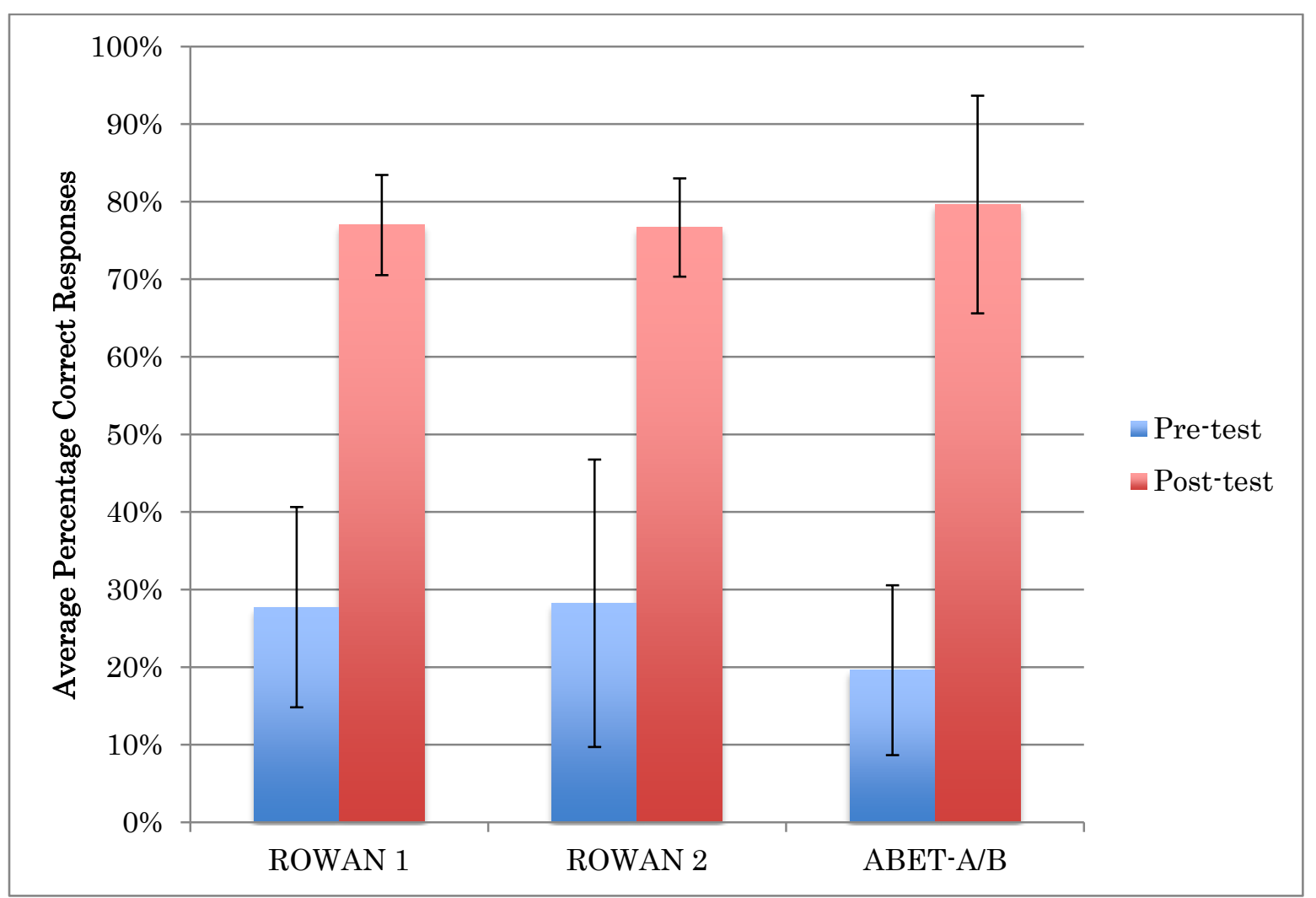

Figure 12. The number of correct pre and post test responses for each learning outcome as described in

Table 3. The percentage included responses for all questions mapped to a particular outcome. Error bars represent $95 \%$ confidence intervals. $\mathrm{p} \leq 0.001$ for each outcome.

There are a few limitations to this analysis. Since there were only 18 students in the class, the sample size is small. The authors are not aware literature describing other methods of teaching drug delivery concepts to first year students; it was therefore not possible to compare our results to another study. Since the Freshman Engineering Clinic course is by design a handson, laboratory-based course, it was not possible to have a comparison group that examined the effectiveness of exploring this topic in an alternate format such as using simulators. Because of the emphasis on the team deliverable, the pre-test and post-test comprised were designed to be short and comprised only eight questions. 


\section{Conclusions}

A simple drug delivery experiment has been developed to introduce students to tablet formulation, swellable matrices, and drug release mechanisms. The experiment was implemented in a multidisciplinary Freshman Engineering course at Rowan University. Students explored the effects of drug loading, polymer composition, and polymer molecular weight on the release profile and the release mechanism of the drug from the tablet. The analysis of experimental data introduces students to spreadsheet calculations, data representation, and mathematical modeling using a power law function.

Students showed significant gains in several areas: the science and art of design by evaluating the work of practicing engineers; new science principles such as mass balances, transport, and materials; application of knowledge of science, math and engineering; and the ability to design and conduct experiments and analyze and interpret data. The gains for each objective between the pre- and post-test ranged from 48-60\%. Thus, the experiment was useful in introducing new concepts and gains were not limited to skills development or application of prior material, as is common with much laboratory instruction.

Several factors enhance the potential transferability of this experiment to other contexts. The experiment was cost-effective, using standard laboratory supplies which allowed multiple teams to construct their own apparatus and to work simultaneously. The analysis can be done using a UV spectrophotometer which is available in most laboratories. Finally, the experimental procedure can easily be led by any Chemical Engineering faculty member or graduate student and does not require a research specialization in drug delivery.

A recent study has provided additional insight on gel layer formation in hydrophilic matrices through direct observation using confocal laser scanning fluorescence microscopy (Mason, 2015). The findings of this study provide direct evidence of how percolation threshold may be linked to the success or failure of early gel layer formation in hydrophilic (HPMC) matrices. With the HPMC matrices, a threshold polymer concentration of $11.5 \% \mathrm{w} / \mathrm{w}$ was required for formation of a continuous gel layer. The development of a continuous gel layer was necessary for attaining desirable extended release characteristics. Based on these findings, it is suggested that future studies determine the percolation threshold of the PEO/caffeine matrix and explore matrix formulations that are above the calculated threshold concentration of polymer. 


\section{Acknowledgements}

This project was funded by grants from the National Science Foundation DUE 1140631. Colorcon graciously donated POLYOX ${ }^{\mathrm{TM}} \mathrm{N}-10$ and 303 resins. The authors gratefully acknowledge the work of the Rowan students, Eileen Batten and Timothy Reardon who participated in developing the experiments and the laboratory handout. 


\section{References}

Bransford, J.D., Brown, A.L, Cocking, R.R. (eds), 2000. How People Learn, National Academy Press, Washington, D.C.

Colombo, P., Bettini, R., Santi, P., and Peppas, N.A., 2000. Swellable Matrices for Controlled Drug Delivery. Pharm. Sci. Tech. Today, 6(3), 198-204.

Cordray, D. S., Harris, T. R. and Klein, S., 2009. A Research Synthesis of the Effectiveness, Replicability, and Generality of the VaNTH Challenge-based Instructional Modules in Bioengineering. J. Eng. Educ., 98(4), 335-348.

Costa, F.O., 2004. Analysis of Formulation Effects in the Dissolution of Ibuprofen Pellets. Int. J. Pharm. 270 (1-2), 9-19.

Dhawan, S., Varma, M. and Sinha, V.R., 2005. High Molecular Weight Poly(ethylene oxide)-Based Drug Delivery Systems, Part I: Hydrogels and Hydrophilic Matrix Systems. Pharm.Tech, May 2005, 72-79.

Dow Chemical Company, 2004. POLYOX ${ }^{\mathrm{TM}}$ Water-Soluble Resins NF in Pharmaceutical Applications, Dow Chemical Company Form No. 326-00013-0802 AMS. Retrieved from: http://msdssearch.dow.com/PublishedLiteratureDOWCOM/dh_0171/0901b80380171e3a.pdf?file path=polyox/pdfs/noreg/326-00013.pdf\&fromPage=GetDoc.

Farrell, S. and Cavanagh, E., 2014. An Introduction to Life Cycle Assessment with Hands-on Experiments for Biodiesel Production and Use, Educ. Chem. Eng. 9(3), e67-e76.

Farrell, S. and Cavanagh, E., 2014. Biodiesel Production, Characterization and Performance: A hands-on, Multidisciplinary Project for First Year Students, Educ. Chem. Eng. 9(2), e21-e31.

Farrell, S. and Hesketh, R.P., 2002. An Introduction to Drug Delivery for Chemical Engineers. Chem. Eng. Educ., 36(3), 198-203.

Greenberg, J. E., Smith, N. T. and Newman, J. H., 2003. Instructional Module in Fourier Spectral Analysis, based on principles of "How People Learn", J. Eng. Educ., 92(2), 155-164.

Gupta, P.K. and Robinson, J.R., 1992. Oral Controlled Release Systems, In A. Kydonieus (ed.), Treatise on Controlled Drug Delivery (pp. 255-313). Marcel Dekker, Inc., New York.

Kim, C.J., 1995. Drug release from compressed hydrophilic POLYOX-WSR tablets, J. Pharm. Sci., 84(3), 303-306.

Korsmeyer, R.W., Gurny, R., Doelker, E., Buri, P., Peppas, N., 1983. Mechanisms of solute release from porous hydrophilic polymers, Int. J. Pharm., 15(1), 25-35.

Langer, R., 1990. New Methods of Drug Delivery. Science 249, 1527-1533.

Levina, M., 2004. The Influence of Excipients on Drug Release from Hydroxypropyl Methylcellulose Matrices. J. of Pharm. Sci., 93(11), 2746-2754.

Liechty, W.B., Kryscio, D.R., Slaughter, B.V., and Peppas, N.A., 2010. Polymers for Drug Delivery Systems, Ann. Rev. Chem. Biomol. Eng. 1, 149-173.

Linsenmeier, R.A.; Kanter, D.E., Smith; H.D. Linsenmeier, K.A; Mckenna, A.F., 2008. Evaluation of a challenge-based human metabolism laboratory for undergraduates, J. Eng. Educ., 97(2), 213-222.

Mason, L.M. , Campiñez, M.D., Pygall, S.R., Burley, J.C., Gupta, P., Storey, D.E., Caraballo, I., Melia, C. D., 2015. The influence of polymer content on early gel-layer formation in HPMC matrices: 
The use of CLSM visualisation to identify the percolation threshold, Eur. J. Pharm. And Biopharm., 94, 485-492.

Norman, J. J., Andrews, S.N., and Prausnitz, M.R., 2011. Undergraduate Laboratory Module on Skin Diffusion. Chem. Eng. Educ., 45(4), 276-282.

NSW Health, 2013. Drug Programs Bureau. Retrieved from: http://www.health.nsw.gov.au/mhdao/mhdao/Factsheets/Pages/caffeine.aspx

Oakley, B., Felder, R.M., Brent, R. and Elhajj, I., 2004. Turning Student Groups into Teams, J. Stud. Centered Teach., 2(1), 10-34.

Pannelay, A.J., 2009. Drug Delivery Technology: Mergers and Acquisitions Activity Expected to Increase. Chemica Oggi, 27(1), 8-9.

Peppas, N.A. and Sahlin, J.J., 1989. A Simple Equation for the Description of Solute Release. III. Coupling of Diffusion and Relaxation. Int. J. Pharm. 57, 169-172.

Prausnitz, M.R. and Bommarius A.S., 2011. Drug Design, Development and Delivery: an Interdisciplinary Course on Pharmaceuticals. Chem. Eng. Educ., 45(1), 47-64.

Ritger, P.L. and Peppas, N.A., 1987a. A Simple Equation for Description of Solute Release I. Fickian and non-Fickian Release from Non-swellable devices in the Form of Slabs, Spheres, Cylinders or Discs. J. Control. Rel., 5(1), 3-36.

Ritger, P.L. and Peppas, N.A., 1987b. A Simple Equation for Description of Solute Release II. Fickian and Anomalous Release from Swellable Devices. J. Control. Rel., 5(1), 37-42.

Roselli, R.J., and Brophy, S.P., 2006. Effectiveness of Challenge-based Instruction in Biomechanics. J. Eng. Educ., 95(4), 311-324.

Saltzman, Mark W., 2001. Drug Delivery: Engineering Principles for Drug Therapy. Oxford University Press, New York. p. 5.

Vernengo, J. and Dahm, K.D., 2012. Two Challenge-based Laboratories for Introducing Undergraduate Students to Biomaterials, Educ. Chem. Eng. 7(1), e14-e21.

Xu, Z., Liang, Y., Tong, Y.W. and Wang, C.H., 2010. Design Project on Controlled-Release Drug Delivery Devices: Implementation, Management, and Learning Experiences. Chem. Eng. Educ. 44(4), 289-298.

Zuurman, K., K. Van der Voort, Maarschalk, K., and Bolhuis, G.K., 1999. Effect of magnesium stearate on bonding and porosity expansion of tablets produced from materials with different consolidation properties. Int. J. Pharm., 179(1), 107-109. 